\title{
EFECTO DE RIZOBACTERIAS EN EL CONTROL DE Rhizoctonia solani EN EL CULTIVO DE PAPA
}

\section{EFFECT OF RHIZOBACTERIA IN THE CONTROL OF Rhizoctonia solani IN POTATO CROPS}

\author{
Jesús Arcos ${ }^{1}$ y Doris Zúñiga ${ }^{2}$
}

\begin{abstract}
Resumen
En condiciones de clima frío y húmedo, una de las enfermedades más importantes que afecta al cultivo de papa es la rizoctoniasis causada por el hongo Rhizoctonia solani Kühn. Con el objetivo de evaluar el efecto de Rizobacterias Promotoras de Crecimiento de Plantas (PGPRs) en $R$. solani y la promoción de crecimiento de plantas en papa, se emplearon dos cepas de Bacillus subtilis (Bac17M8: T1 y Bac17M9: T2), nativas de la región altiplánica del Perú y $B$. amyloliquefaciens de Bolivia (T3); además, se evaluó suelo infestado con $R$. solani sin rizobacteria (T4) y sin rizobacteria ni presencia de $R$. solani (T5), en condiciones de invernadero. Las plántulas de la variedad Ccompis y Andina inoculadas con las tres cepas de PGPRs presentaron menor mortalidad (en promedio 18.90\% y $12.13 \%$ en Ccompis y Andina, respectivamente) en comparación con las no inoculadas (28.02\% y 19.89\% en Ccompis y Andina, respectivamente). Así mismo, en ambas variedades, los tubérculos cosechados de las parcelas inoculadas con rizobacterias también presentaron menores valores de incidencia (en promedio 15.19\% y 6.99\% en Ccompis y Andina, respectivamente) y severidad (5.75 a $9.06 \%$ y 5.73 a $7.31 \%$ en Ccompis y Andina, respectivamente), en comparación con los tubérculos cosechados de la parcela no inoculada que presentaron incidencia de 25.24\% y 12.78\% en Ccompis y Andina, respectivamente, y una severidad mayor a $30 \%$, en ambas variedades.

Palabras clave: papa, Bacillus subtilis, PGPRs, control, Rhizoctonia solani.
\end{abstract}

\begin{abstract}
Under cold and wet weather conditions, one of the most important diseases that affect potato crops is the rhizoctoniasis caused by the fungus Rhizoctonia solani Kühn. Aiming to assess the effect of Plant Growth Promoting Rhizobacteria (PGPRs) in R. solani and to promote plant growth in potatoes, two strains of Bacillus subtilis (Bac17M8: T1 and Bac17M9: T2), native to the Peruvian plateau and B. amyloliquefaciens from Bolivia (T3), were used. Furthermore, soil infested with $R$. solani, without rizobacteria (T4) and without rizobacteria nor $R$. solani (T5) under greenhouse conditions was evaluated. The seedlings of Ccompis and Andina varieties inoculated with the three strains of PGPR showed lower mortality (average 18.90\% and $12.13 \%$ in Ccompis and Andina, respectively) compared to non-inoculated (28.02\% and $19.89 \%$ in Ccompis and Andina, respectively). Likewise, in both varieties, the tubers harvested from inoculated plots with rhizobacteria also presented lower incidence values (average 15.19\% and 6.99\% in Ccompis and Andina, respectively) and severity (5.75 to $9.06 \%$ and 5.73 to $7.31 \%$ in Ccompis and Andina, respectively), compared to tubers harvested from the non-inoculated plot that showed an incidence of $25.24 \%$ and $12.78 \%$ in Ccompis and Andina, respectively, and a severity greater than $30 \%$ in both varieties.
\end{abstract}

Key words: potato, Bacillus subtilis, PGPRs, control, Rhizoctonia solani.

\section{Introducción.}

En las condiciones ambientales de la región andina, el cultivo de la papa enfrenta numerosos problemas, tales como la incidencia de heladas, sequías, granizadas, plagas y enfermedades. Muchas de las enfermedades son causadas por hongos cuyas estructuras de resistencia se encuentran en el suelo, y ocasionan pérdidas económicamente significativas en la producción de este cultivo, pudiendo alcanzar hasta 20\% (Torres, 2002). En la papa, se han identificado más de 30 enfermedades causadas por hongos; de las cuales, en las condiciones de clima frío y húmedo, una de las enfermedades más importantes es la 
rizoctoniasis causada por Rhizoctonia solani Kühn (Hooker, 1980).

Rhizoctonia solani es un patógeno de distribución mundial que ocasiona pérdidas económicas importantes en la mayoría de las plantas perennes y anuales, incluyendo casi todos los cultivos hortícolas; entre las enfermedades comúnmente causadas es el llamado ahogamiento de las plántulas y la pudrición de las raíces (Agrios, 1998). En el Perú, esta enfermedad afecta a un gran número de cultivos, tales como: fréjol, cebada, algodón, tomate, papa, etc., causando daños serios durante cualquier estado de desarrollo de la planta.

La "rizoctoniasis" denominada también "chancro del tallo” ó “costra negra” (Rhizoctonia solani Kühn) es una de las enfermedades fungosas que está presente en todas las zonas productoras de papa del Perú (Hooker, 1980; Torres, 2002). En los departamentos de Puno, Cusco, Ayacucho y Junín, la incidencia de esta enfermedad puede afectar la calidad de los tubérculos en forma significativa. En las variedades susceptibles la incidencia puede alcanzar hasta $80 \%$ y la severidad 35\% (INIA, 2013). En el brotamiento, $R$. solani infecta los brotes del tubérculo-semilla en los estados pre y post emergente, anulando o retardando su emergencia, teniendo como consecuencia fallas en la emergencia de las plantas, desigualdad en el crecimiento, plantas débiles, las plantas adultas presentan lesiones hundidas de color marrón oscuro en las raíces, reducción del crecimiento de estolones y tallo aéreo, lo cual afecta procesos como la absorción del agua y nutrientes del suelo y la translocación de fotoasimilados hacia los órganos de reserva; provocando una reducción del rendimiento y formación de tubérculos aéreos, y en casos severos resulta en marchitez y muerte (Torres, 2002).

Las plántulas procedentes de semilla sexual y transplantadas al campo son severamente afectadas por un complejo de patógenos, entre los cuales se encuentra $R$. solani, que causa el síntoma del ahogamiento y muerte de plántulas antes o poco después de que han emergido del suelo, el hongo ataca el tallo ocasionando pudriciones blandas, las cuales se inician en la parte basal de los tallos. Con el avance de las lesiones las plántulas se debilitan y mueren; en algunos casos, el porcentaje de plántulas muertas puede llegar hasta 70\% (Martin \& Torres, 1989).

Los tubérculos afectados por $R$. solani presentan lo que se conoce como "ojos ciegos" y masas compactas de micelio llamadas esclerocios en la superficie, de color negro a castaño oscuro, éstas presentan variabilidad en tamaño y forma, y son fácilmente extraíbles. Torres (2002) reporta que estas estructuras son producidas solamente por los grupos de anastomosis GA3 y GA7.

Por otro lado, para el control de esta enfermedad, no existe ningún fungicida efectivo. Gutierrez \& Torres (1990) demostraron que el control biológico de
$R$. solani con Rhizoctonia binucleada reduce la muerte de plántulas de papa provenientes de semilla sexual cuando éstas son transplantadas a campos infectados con $R$. solani.

La papa es uno de los principales cultivos del Perú, tanto por la superficie sembrada como por la población dedicada a su cultivo. Se cultiva en 19 de los 24 departamentos que tiene el Perú, desde el nivel del mar hasta los 4,500 metros de altura, encontrándose las áreas agrícolas de mayor producción en los departamentos de Puno, Huánuco, Cusco, Cajamarca, Huancavelica, Junín, entre otras. A nivel nacional se siembran más de 20 variedades comerciales de papa mejorada siendo las más importantes Canchán INIA, Andina, Perricholi, Yungay, Chaska, CICA, Única y últimamente Serranita; y dentro de las papas nativas destacan Huagalina de Cajamarca, Amarilla Tumbay de Huanuco, Peruanita, Huayro, Huamantanga del centro, Ccompis, Imilla Negra, entre otras (MINAG, 2010). La variedad Ccompis es una nativa de alta calidad culinaria, sembrada extensivamente en Puno por su tolerancia a factores abióticos y bióticos adversos, con 130 días de periodo vegetativo aproximadamente, y la Andina es una variedad mejorada, también sembrada extensivamente por su adaptación a las condiciones agroecológicas de la región altiplánica del Perú, con 150 días de periodo vegetativo aproximadamente (INIA, 2013).

Durante las dos últimas décadas, la alternativa de regulación biológica con rizobacterias ha incrementado significativamente, las cuales han sido denominadas Rizobacterias Promotoras de Crecimiento de Plantas (PGPRs) (Kloepper \& Schroth, 1978). Las PGPRs son microorganismos del suelo, generalmente bacterias y hongos, que se relacionan fisiológica y bioquímicamente de manera natural con las raíces de las plantas; facilitan de manera directa o indirecta la disponibilidad de determinados nutrientes para las plantas, tales como nitrógeno, fósforo y hierro (Fulchieri \& Frioni, 1994).

Los metabolitos secundarios producidos por algunas cepas de las PGPRs pueden funcionar como antagónicos (involucran aspectos de control biológico, suprimen o inhiben el crecimiento de microorganismos fitopatógenos) mediante la producción de sideróforos, antibióticos, acción de enzimas líticas (glucanasas, quitinasas) o inducción de mecanismos de resistencia (Bashan, 1998; Buchenauer, 1998). Varios estudios reportaron que las PGPRs incrementan la resistencia en plantas frente a las enfermedades fungosas, bacterianas y virales (Liu et al., 1995; Maurhofer et al., 1998), insectos (Zehnder et al., 1997a, b) y nematodos (Sikora, 1988); y dentro de los microorganismos biocontroladores más importantes se encuentran los hongos de los géneros Gliocladium y Trichoderma y las rizobacterias de los 
géneros Pseudomonas, Bacillus y Agrobacterium (Fernández-Larrea, 2001).

Jiménez et al. (2001) identificaron en el cultivo de papa, que la bacteria $B$. subtilis inhibía prácticamente todos los grupos de anastomosis de $R$. solani, algunas cepas de Fusarium sp. y de Phytophthora infestans. También demostraron que B. subtilis es una PGPR, ya que aumenta la cantidad y calidad de tubérculos. Por todo ello, el objetivo del presente trabajo fue evaluar el efecto de las rizobacterias sobre $R$. solani en dos variedades de papa, mediante la determinación/medición de mortalidad de plantas, infección y severidad daño en tubérculos, en condiciones de invernadero.

\section{Materiales y métodos.}

Localización del ensayo.

La investigación se realizó en la Estación Experimental del INIA situada en la localidad de Salcedo, distrito, provincia y departamento de Puno; ubicada a 3820 msnm, latitud Sur $15^{\circ} 14^{\prime} 35^{\prime \prime}$ y longitud Oeste $70^{\circ}$ 43' 30', en condiciones de invernadero con temperaturas máxima y mínima promedio de $25.50^{\circ} \mathrm{C}$ y $12.25^{\circ} \mathrm{C}$, respectivamente, y con humedad relativa de $78 \%$, Con el fin de evaluar el efecto de rizobacterias en $R$. solani y la promoción de crecimiento de plantas en papa, se emplearon dos cepas de B. subtilis (Bac17M8: T1 y Bac17M9: T2), aisladas de la rizósfera del cultivo de papa de las zonas productoras de Puno (Calvo \& Zúñiga, 2010; Calvo et al., 2010; Calvo et al., 2008) у B. amyloliquefaciens de Bolivia (Bac Bolivia: T3); además, se evaluó suelo infestado con $R$. solani sin rizobacteria (T4) y sin rizobacteria ni presencia de $R$. solani (T5). En total fueron cinco tratamientos. La inoculación se realizó sobre plantas in vitro de la variedad Ccompis y Andina, que fueron proporcionadas por el laboratorio de cultivo de tejidos del INIA-Puno.

Diseño experimental.

Para el análisis estadístico se utilizó un diseño experimental de bloques completos al azar (BCA), con cinco tratamientos, cuatro repeticiones $\mathrm{y}$ dos variedades.

Transplante de plántulas in Vitro e inoculación de rizobacterias.

El transplante de las plántulas in vitro de papa, fue realizado en cada unidad experimental que consistió de $1 \mathrm{~m}^{2}$ de suelo infestado con $R$. solani (o sustrato según tratamiento) de profundidad aproximada de 15 cm (45 plántulas $/ \mathrm{m}^{2}$ ), constituyendo los tratamientos correspondientes, bajo condiciones de invernadero. Se dispuso de suelo infestado en cada unidad experimental, este suelo presentó un valor medio de materia orgánica (2.35\%), pH moderadamente ácido (5.77), el contenido de fósforo y potasio fue de 23.80 y 238.99 ppm, respectivamente. Para el tratamiento con sustrato sin presencia de $R$. solani y sin rizobacteria se utilizó sustrato desinfectado por solarización. Este sustrato consistió de una mezcla de arena, compost y suelo de capa arable y de color negro, en una proporción de 1:2:2 y presentó un valor medio en contenido de materia orgánica (3.4\%), un valor moderadamente ácido de $\mathrm{pH}$ (5.56) y un contenido de fósforo y potasio de 23.75 y 245.60 ppm, respectivamente.

La inoculación de las rizobacterias se realizó con una jeringa estéril en el momento del trasplante, dosificando $5 \mathrm{ml}$ de la suspensión en la rizósfera de las plántulas con la concentración de 1 x $10^{8} \mathrm{ufc} / \mathrm{ml}$ (Oswald et al., 2010); luego, usando guantes estériles se cubrieron las raíces inoculadas con una pequeña capa de suelo asegurando que las raíces estén en contacto íntimo con el suelo y/o sustrato.

Manejo de plántulas.

Antes del transplante, las plántulas crecidas in vitro que se encontraban en magentas se colocaron en bandejas con agua para su aclimatación y para que puedan tener mayor vigor, por un periodo de 72 horas. Después de 30 días del transplante e inoculación en las plántulas, se realizó el primer aporque (adición de suelo infestado/sustrato correspondiente a cada tratamiento), coincidiendo con la primera fertilización (140-120-100 kg/ha de $\mathrm{N}, \quad \mathrm{P}_{2} \mathrm{O}_{5} \quad$ y $\quad \mathrm{K}_{2} \mathrm{O}$ ). Posteriormente, se realizaron tres aporques y dos fertilizaciones a intervalos de 30 días. La fertilización (mezcla de Úrea, Fosfato Diamónico y Cloruro de Potasio) se realizó de forma uniforme alrededor de las plantas, para luego ser cubiertas con una capa de suelo o sustrato. Para evitar la caída de las plantas, se colocaron tutores de carrizo.

Después del transplante, se adicionó aproximadamente 8 a 10 litros de agua por $\mathrm{m}^{2}$ para regar durante 15 días a intervalos de 3 días, posteriormente se suministró riego interdiario (12 a 15 litros de agua por $\mathrm{m}^{2}$ hasta 60 días); a partir de los 63 días después de la siembra, cuando las plantas se encontraban en el inicio de la floración, el riego fue cada 3 días, aplicándose 15 a 20 litros por $\mathrm{m}^{2}$ hasta el final de la floración (120 días después del trasplante). Parámetros evaluados.

Los parámetros evaluados fueron: mortalidad de plántulas (10 días después del trasplante), altura de planta en floración (90-115 días), el rendimiento $\left(\mathrm{Kg} / \mathrm{m}^{2}\right)$ de tubérculos y la incidencia y severidad (Torres, 2002) causada por $R$. solani (incidencia es el porcentaje de tubérculos con esclerocios y severidad es el porcentaje de área cubierta con esclerocios en los tubérculos) se realizó al momento de la cosecha (140 días). Con los datos obtenidos se realizó un análisis de varianza y para aquellas variables que presentaron diferencias significativas entre los promedios de los tratamientos se realizó la prueba de comparación de medias de LSD con un nivel de significancia de 0.05, tanto para los efectos principales así como para los efectos de interacción entre ellos. 


\section{Resultados y discusión.}

Las plántulas de la variedad Ccompis y Andina inoculadas con las cepas de rizobacterias ante la presencia de $R$. solani presentaron menor mortalidad (18.90\% y 12.13\%, en Ccompis y Andina, respectivamente) estadísticamente significativas, a los 10 días después del transplante, diferenciándose en $9.12 \%$ y $7.76 \%$, respectivamente, con respecto a la ausencia de rizobacterias (28.02\% y $19.89 \%$, en Ccompis y Andina, respectivamente) (Figuras 1 y 2). En la variedad Ccompis la cepa con mejor efecto de inhibición de la infección fue $B$. amyloliquefaciens con una disminución de $12.71 \%$ de plántulas muertas que en el suelo infestado no inoculado y en la variedad Andina la cepa con mejor inhibición fue Bac17M8 con una disminución de $9.13 \%$ que en el suelo no inoculado. Calvo et al. (2010) reportaron que la cepa Bac17M8, en condiciones de in Vitro, inhibió el crecimiento de $R$. solani en $84.52 \%$. En ambas variedades, la parcela sin rizobacteria ni presencia de $R$. solani no presentó muerte de plántulas (Figuras 1, 2).

En cuanto a la altura de planta, no se encontraron diferencias significativas entre las dos variedades trabajadas (Ccompis y Andina). Así mismo, se observó que las plantas inoculadas con la cepa Bac17M8 fueron de menor tamaño estadísticamente significativas comparadas con las de los otros tratamientos (Tabla 1). Sin embargo, esta cepa inhibió significativamente el desarrollo de la infección por $R$. solani, en la variedad de papa Andina (Figura 2).

Los rendimientos de tubérculos total (en peso) y sin infección con $R$. solani, tanto en la variedad Ccompis como en la variedad Andina no presentaron diferencias estadísticas significativas entre tratamientos. Sin embargo, los rendimientos de las parcelas inoculadas con las rizobacterias Bac17M9 y

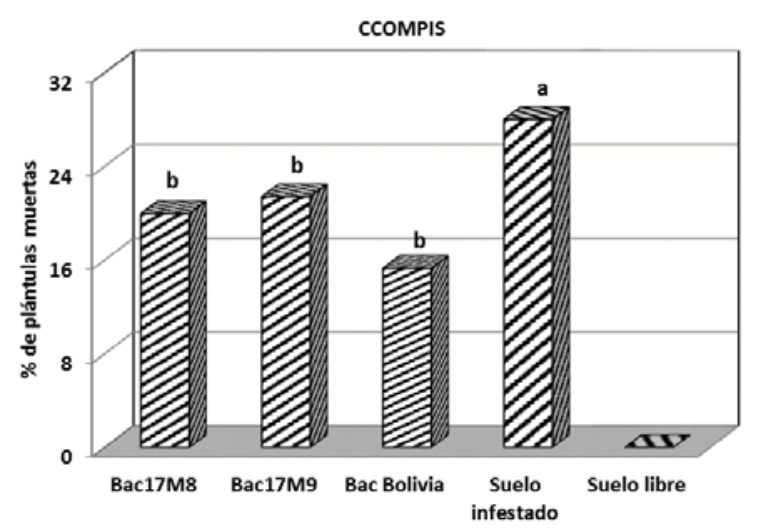

*Tratamientos seguidos por letras iguales no difieren significativamente $(\mathrm{p}<0.05)$.

Figura 1. Efecto de rizobacterias en la mortalidad de plántulas por $R$. solani en la variedad Ccompis.

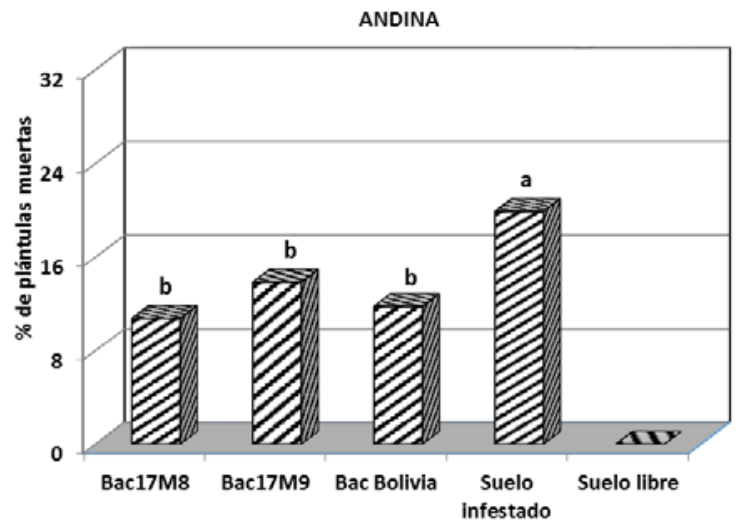

*Tratamientos seguidos por letras iguales no difieren significativamente $(\mathrm{p}<0.05)$.

Figura 2. Efecto de rizobacterias en la mortalidad de plántulas por $R$. solani en la variedad Andina.

B. amyloliquefaciens de Bolivia se incrementaron en $26.24 \%$ y 23.40\%, respectivamente, en comparación con el tratamiento de suelo sin rizobacteria y con presencia de $R$. solani. En condiciones de campo, Oswald et al. (2010) reportaron un incremento en el rendimiento de un 25 a $40 \%$ en ensayos con otras cepas de Bacillus (Bac2 y Act4) comparado con el control orgánico, en variedades Ccompis y Andina.

Respecto a la incidencia de la enfermedad, en un suelo infestado con $R$. solani, en la variedad Ccompis, los tubérculos cosechados de las parcelas inoculadas con cepas de Bac17M8, Bac17M9 y $B$. amyloliquefaciens de Bolivia presentaron menores porcentajes de tubérculos infectados con $R$. solani (en promedio 15.19\%) en comparación con los tubérculos cosechados de la parcela que no fue inoculada con rizobacterias (25.24\%), con una disminución de $10.05 \%$ de tubérculos infectados como efecto del antagonismo con $R$. solani (Figura 3). De manera similar, en la variedad Andina los tubérculos cosechados de las parcelas inoculadas con cepas de rizobacterias presentaron menores porcentajes de tubérculos con síntomas de rizoctoniasis (en promedio 6.99\%), comparados con los tubérculos cosechados de la parcela no inoculada (12.78\%), con un porcentaje de $5.79 \%$ menos de tubérculos infectados como efecto de la supresión o inhibición del fitopatógeno (Figura 4).

En la variedad Ccompis, en las parcelas inoculadas con las cepas de rizobacterias Bac17M8, Bac17M9 y B. amyloliquefaciens de Bolivia, los porcentajes de tubérculos infectados fueron de 12.76, $15.75 \mathrm{y}$ $17.06 \%$, respectivamente, comparado con el porcentaje de tubérculos infectados de la parcela no inoculada (25.24\%); mientras que en la variedad Andina, los porcentajes de tubérculos infectados fueron de $7.51,7.73$ y $5.75 \%$ cuando las parcelas fueron inoculadas con las cepas de rizobacterias 
Tabla 1. Altura de plantas $(\mathrm{m})$ y rendimiento $\left(\mathrm{kg} / \mathrm{m}^{2}\right)$ de las plántulas inoculadas con rizobacterias y las no inoculadas en las variedades Ccompis y Andina.

\begin{tabular}{|c|c|c|c|}
\hline Orden & Tratamiento & $\begin{array}{c}\text { Altura } \\
\text { planta } \\
(\mathbf{m})^{\mathrm{a}}\end{array}$ & $\begin{array}{c}\text { Rendimiento } \\
\left(\mathrm{kg} / \mathrm{m}^{2}\right)^{\mathrm{b}}\end{array}$ \\
\hline 1 & Suelo libre de $R$. solani & $1.55 \mathbf{a}$ & 3.89 \\
\hline 2 & Bac Bolivia* & $1.48 \mathrm{a}$ & 3.48 \\
\hline 3 & Bac17M9* & $1.45 \mathbf{a}$ & 3.56 \\
\hline 4 & Suelo infestado sin rizobacteria & $1.42 \mathbf{a} \mathbf{b}$ & 2.82 \\
\hline 5 & Bac17M8* & $1.31 \mathbf{b}$ & 2.91 \\
\hline
\end{tabular}

Tratamientos seguidos por letras iguales no difieren significativamente $(\mathrm{p}<0.05)$.

*Inoculado en suelo infestado con $R$. solani, a) evaluada a la floración, b) evaluado a la cosecha.

Bac17M8, Bac17M9 у B. amyloliquefaciens de Bolivia, respectivamente, en comparación a la parcela no inoculada (12.78\%) (Figuras 3 y 4).

Respecto a la severidad de la enfermedad, el porcentaje de infección en los tubérculos cosechados de las parcelas donde las plántulas in vitro fueron inoculadas con cepas de rizobacterias varió de 5.75 a $9.06 \%$ en la variedad Ccompis, mientras que en la variedad Andina fue de 5.73 a 7.31\%, en comparación con los tubérculos de las parcelas no inoculadas con cepas de rizobacterias que presentaron una severidad de daño mayor a 30\%, en ambas variedades (Figuras 3 y 4).

En ambas variedades de papa, las tres cepas de rizobacterias controlaron al fitopatógeno de $R$. solani observado por una reducción del \% de muerte de plántulas, y por la disminución del \% de tubérculos infectados en comparación al tratamiento no inoculado, resultando mejor la cepa Bac17M8 en la var. Ccompis y la cepa de Bolivia en la var. Andina, para el segundo parámetro. Así también el rendimiento en peso de tubérculos, fue mayor cuando se inocularon las rizobacterias, destacando la cepa Bac17M9. Estudios en condiciones de in Vitro reportaron que la cepa

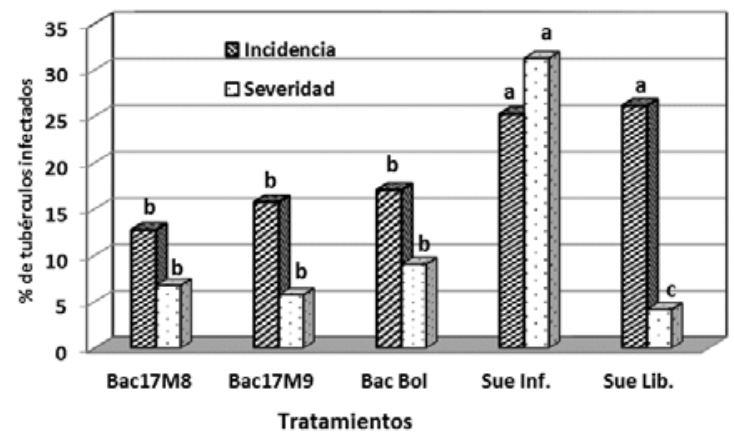

*Tratamientos seguidos por letras iguales no difieren significativamente $(\mathrm{p}<0.05)$.

Figura 3. Porcentaje de tubérculos infectados por $R$. solani en la variedad Ccompis.
Bac17M8 tiene la capacidad de inhibir el crecimiento de $R$. solani en un porcentaje de $84.52 \%$ y de Fusarium solani en un 70.11\%; también es importante indicar que esta cepa tiene la capacidad de solubilización de fosfato (Calvo et al., 2010). En otros estudios del efecto de una colección de cepas de Bacillus en el control de $R$. solani, de 9.5 hasta el 36\% fueron antagónicas con este fitopatógeno (Cho et al., 2007; Mojica-Marín et al., 2008), se puede decir que estos resultados de las investigaciones realizadas por tales personas corroboran los resultados obtenidos.

Los tubérculos cosechados de la parcela inoculada con la cepa Bac17M8 presentaron una severidad de $6.76 \%$, estos tubérculos presentaron esclerocios de tamaño pequeño ( 0.1 a $2.5 \mathrm{~mm}$ de diámetro) y de color marrón oscuro, en comparación a los esclerocios de los tubérculos de la parcela sin rizobacterias, que fueron de tamaño grande (> a $2.5 \mathrm{~mm}$ de diámetro), de color negro y una severidad de daño mayor a $30 \%$. Algunos mecanismos para control biológico de enfermedades pueden incluir: competición por sitios de infección y nutrientes, parasitismo sobre patógenos, es decir destrucción de patógenos fungosos por la acción de enzimas líticas (por ejemplo quitinasa y $\beta-1$, 3 -glucanasa) que degradan la pared celular y factores antifúngicos no caracterizados (Lim et al., 1991; Fridlender et al., 1993; Kloepper, 1993, 1994, 1996; Potgieter \& Alexander, 1996; Glick, 1995; Velazhahan et al., 1999; Zahir et al., 2004) o producción de metabolitos secundarios por el microorganismo antagonista; tales como, sideróforos, antibióticos, bacteriocinas, enzimas y otros compuestos que suprimen o inhiben la acción del patógeno (Leifert et al., 1995).

En el tratamiento sin rizobacteria ni presencia de $R$. solani se observaron tubérculos con incidencias de

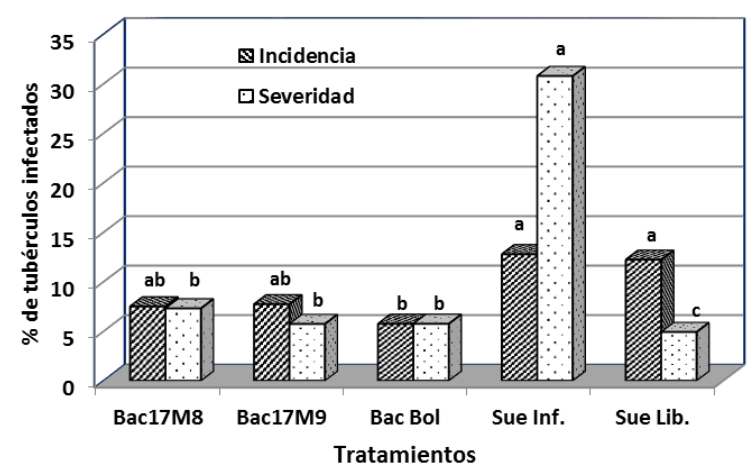

*Tratamientos seguidos por letras iguales no difieren significativamente $(\mathrm{p}<0.05)$.

Figura 4. Porcentaje de tubérculos infectados por $R$. solani en la variedad Andina. 
$26.16 \%$ y $12.22 \%$ en Ccompis y Andina, respectivamente; sin embargo, el porcentaje de severidad de daño fue menor a $5 \%$, en ambas variedades (Figuras 3 y 4); se destaca que en la parcela infestada con $R$. solani los tubérculos presentaron una severidad mayor a 30\%. Una incidencia menor del $5 \%$ en la parcela libre de $R$. solani se debe posiblemente a que la desinfección o esterilización del sustrato no fue eficiente. El sustrato utilizado es una mezcla de arena, musgo y tierra orgánica, que muchas veces está contaminado con huevos de insectos, semillas de malezas o patógenos como R. solani, Spongospora subterranea y otros que deben ser eliminados a través de una metodología de desinfección eficiente antes de ser usados como tal; sino se utiliza una metodología o esterilizante efectivo pueden presentarse deficiencias en la eliminación de microorganismos perjudiciales (CIP, 2008).

El análisis de los resultados de las Figuras 3 y 4 permite deducir que en condiciones de invernadero y cuando las plántulas son inoculadas con rizobacterias in vitro, la variedad Ccompis presentó mayor incidencia de daño por $R$. solani, que la variedad Andina; sin embargo, la severidad fue similar en ambas variedades.

\section{Conclusiones.}

Las cepas de B. subtilis (Bac17M8 y Bac17M9) y $B$. amyloliquefaciens nativas de la región altiplánica del Perú y Bolivia, inoculadas a plántulas de dos variedades de papa (Ccompis y Andina), tienen la capacidad de inhibir la infección por $R$. solani, posiblemente a través de algún mecanismo de acción antagónico o por resistencia inducida.

\section{Agradecimientos.}

Al Centro Internacional de la Papa (CIP), Concejo Nacional de Ciencia y Tecnología (Procyt-Concytec), Laboratorio de Ecología Microbiana y Biotecnología de la UNALM y al Instituto Nacional de Innovación Agraria (INIA).

\section{Literatura citada.}

Agrios G. N. 1998. Fitopatología. Editorial Limusa, Grupo Noriega Editores. Segunda Edición. México, D. F. 838 pp.

Bashan Y. 1998. Inoculants of plant growth promoting bacteria for use in agriculture. Biotech. Advances 16: 729-770.

Buchenauer H. 1998. Biological control of soil-borne diseases by rhizobacteria. Z. Pflanzenk.Pflanzens. 105: 329-348.

Calvo P. \& Zúñiga D. 2010. Caracterización fisiológica de cepas de Bacillus spp. aisladas de la rizósfera de papa (Solanum tuberosum). Ecol. Apl. 9(1): 31-39.

Calvo P., Ormeño-Orrillo E., Martinez-Romero E. \& Zúñiga D. 2010. Characterization of Bacillus isolates of potato rhizosphere from Andean soils of Peru and their potential PGPR characteristics. Braz. J. Microbiol. 41: 899-906.
Calvo P., Reymundo L. \& Zúñiga D. 2008. Estudio de las poblaciones microbianas de la rizósfera del cultivo de papa (Solanum tuberosum) en zonas altoandinas. Ecol. Apl. 7(1,2): 141-148.

Centro Internacional de la Papa (CIP). División de Manejo Integrado de Cultivos. 2008. Alternativas al uso de bromuro de metilo en la producción de semilla de papa de calidad. Documento de trabajo 2007-2. Lima, Perú. $53 \mathrm{p}$.

Cho K. M., Hong S. Y., Lee S. M., Kim Y. H., Kahng G. G., Lim Y. P., Kim H. \& Yun H. D. 2007. Endophytic bacterial communities in ginseng and their antifungal activity against pathogens. Microb. Ecol. 54 (2): 341351.

Fernández-Larrea O. 2001. Microorganismos antagonistas para el control fitosanitario. Manejo Integrado de Plagas (Costa Rica). N 62: 96-100.

Fridlender M., Invar J. \& Chet I. 1993. Biological control of soil-borne plant pathogens by a B-1,3-glucanase producing Pseudomonas cepacia. Soil Biol. Biochem. 25: 1211-1221.

Fulchieri M. \& Frioni L. 1994. Azospirillum inoculation on maize effect of yield in field experiment in central Argentina. Soil Biol. Biochem. 26: 921-923.

Glick B. R. 1995. The enhancement of plant growth by free living bacterial. Can. J. Microbiol. 41: 109-117.

Gutierrez Patricia \& Torres H. 1990. Control biológico de Rhizoctonia solani con Rhizoctonia binucleada. Fitopatología 25: 45-50

Hooker W. J. 1980. Compendio de Enfermedades de la Papa. Centro Internacional de la Papa.Lima, Perú. 166 p.

Instituto Nacional de Innovación Agraria del Perú. 2013. Plan Estratégico de Mejoramiento Genético del Programa Nacional de Innovación Agraria en Raíces y Tuberosas-Papa. DIA. Sub-dirección de Cultivos. Lima, Perú. 37 p.

Jiménez Rocío, Virgen G., Tabares S. \& Olalde V. 2001. Bacterias promotoras del crecimiento de plantas: agrobiotecnología. Avance y Perspectiva 20: 395-400.

Kloepper J. W. 1996. Biological control agents vary in specificity for host, pathogen control, ecological habitat and environmental conditions. Bio. Sci. 46: 406-409.

Kloepper J. W. 1994. Plant Growth Promoting Rhizobacteria (other system). Pp: 135-166. In Y. Okon, Ed. Azospirillum/Plant Association. CRC Press, Boca Raton. Florida, USA.

Kloepper J. W. 1993. Plant growth promoting rhizobacteria as biological control agents. Pp: 255-274. In F. B. Metting Jr., Ed. Soil Microbial Ecology. Dekker, New York, USA.

Kloepper J. W. \& Schroth M. N. 1978. Plant growthpromoting rhizobacteria on radishes. In: Proceedings of the Fourth International Conference on plant pathogenic bacteria, INRA. Angers (Francia) 2: 879-882.

Leifert C., Li H., Chidburee S., Hampson S., Workman S., Sigee D., Epton H. \& Harbour A. 1995. Antibiotic production and biocontrol activity by Bacillus subtilis CL27 and Bacillus pumilus CL45. J. Appl. Bacteriol. 78: 97-108.

Lim H., Kim Y. \& Kim S. 1991. Pseudomonas stutzeri YLP-1 genetic transformation and antifungal mechanism against Fusarium solani, an agent of plant root rot. Appl. Environ. Microbiol. 57: 510-516. 
Liu L., Kloepper J. W. \& Tuzun S. 1995. Induction of systemic resistance in cucumber against bacterial angular leaf spot by plant growth-promoting rhizobacteria. Phytopathology 85: 695-698.

Martin C \& Torres H. 1989. Control of Rhizoctonia and other soil-borne diseases of TPS. Pp: 191-205. In Fungal Diseases of the Potato. Report of Planning Conference on Fungal Diseases. CIP. Lima, Perú. September 21-25.

Maurhofer M., Reimann C., Sacherer S. P., Heebs S., Haas D. \& Defago G. 1998. Salicylic acid biosynthetic genes expressed in Pseudomonas fluorescens strain P3 improve the induction of systemic resistance in tobacco against necrosis virus. Phytopathology 88: 678-684.

Ministerio de Agricultura y Riego del Perú. 2010. Papa, Día Nacional de la Papa. DGCA. Cadena Agroproductiva. Boletín 1. Lima, Perú. 43 p.

Mojica-Marín V., Luna-Olvera H. A., Sandoval-Coronado C. F., Pereyra-Alférez B., Morales-Ramos L. H., Hernández-Luna C. E. \& Alvarado-Gomez O. G. 2008. Antagonistic activity of selected strains of Bacillus thuringiensis against Rhizoctonia solani of chili pepper. Afr. J. Biotechnol. 7 (9): 1271-1276.

Oswald A., Calvo P., Zúñiga D. \& Arcos J. 2010. Evaluating soil rhizobacteria for their ability to enhance plant growth and tuber yield in potato. Ann. Appl. Biol. 157: 259-271.
Potgieter H. \& Alexander M. 1996. Susceptibility and resistance of several fungi to microbial lysis. J. Bacteriol. 91: 1526-1532.

Sikora R. A. 1988. Interrelationship between plant health promoting rhizobacteria, plant parasitic nematodes and soil microorganisms. Med. Fac. Landbouww. Rijkuniv. Gent 53/2b: 867-878.

Torres H. 2002. Manual de las enfermedades más importantes de la papa en el Perú. Centro Internacional de la Papa. Lima, Perú. 59 p.

Velazhahan R., Samiyappan R. \& Vidhyasekaran P. 1999. Relationship between antagonistic activities of Pseudomonas fluorescens isolates against Rhizoctonia solani and their production of lytic enzymes. J. Plant Dis. Prot. 106: 244-250.

Zahir Z. A., Arshad M. \& Frankenberger W. 2004. Plant growth promoting rhizobacteria: Applications and perspectives in Agriculture. Advances in Agronomy 81: 97-168.

Zehnder G., Kloepper J. W., Yao C. \& Wei G. 1997a. Induction of systemic resistance in cucumber against cucumber beetles (Coleoptera: Chrysomelidae) by plant growth-promoting rhizobacteria. J. Econ. Entomol. 90: 391-396.

Zehnder G., Kloepper J. W., Tuzun S., Yao C., Wei G., Chambliss O. \& Shelby R. 1997b. Insect feeding on cucumber mediated by rhizobacteria-induced plant resistance. Entomol. Exp. Appl. 83: 81-85.

\footnotetext{
${ }^{1}$ Estación Experimental Agraria Illpa-Puno. Instituto Nacional de Innovación Agraria. Av. La Molina ํㅜ 1981. Lima, Perú.

${ }^{2}$ Laboratorio de Ecología Microbiana y Biotecnología, Dpto. de Biología, Fac. de Ciencias, Universidad Nacional Agraria La Molina. Lima, Perú. dzuniga@lamolina.edu.pe
} 